\title{
Sequência metodológica para a estimativa da iluminação natural e suas implicações em sistemas de avaliação de desempenho de edificações
}

\author{
Methodological sequence to predict daylighting and its \\ implications for the energy performance evaluation of \\ buildings
}

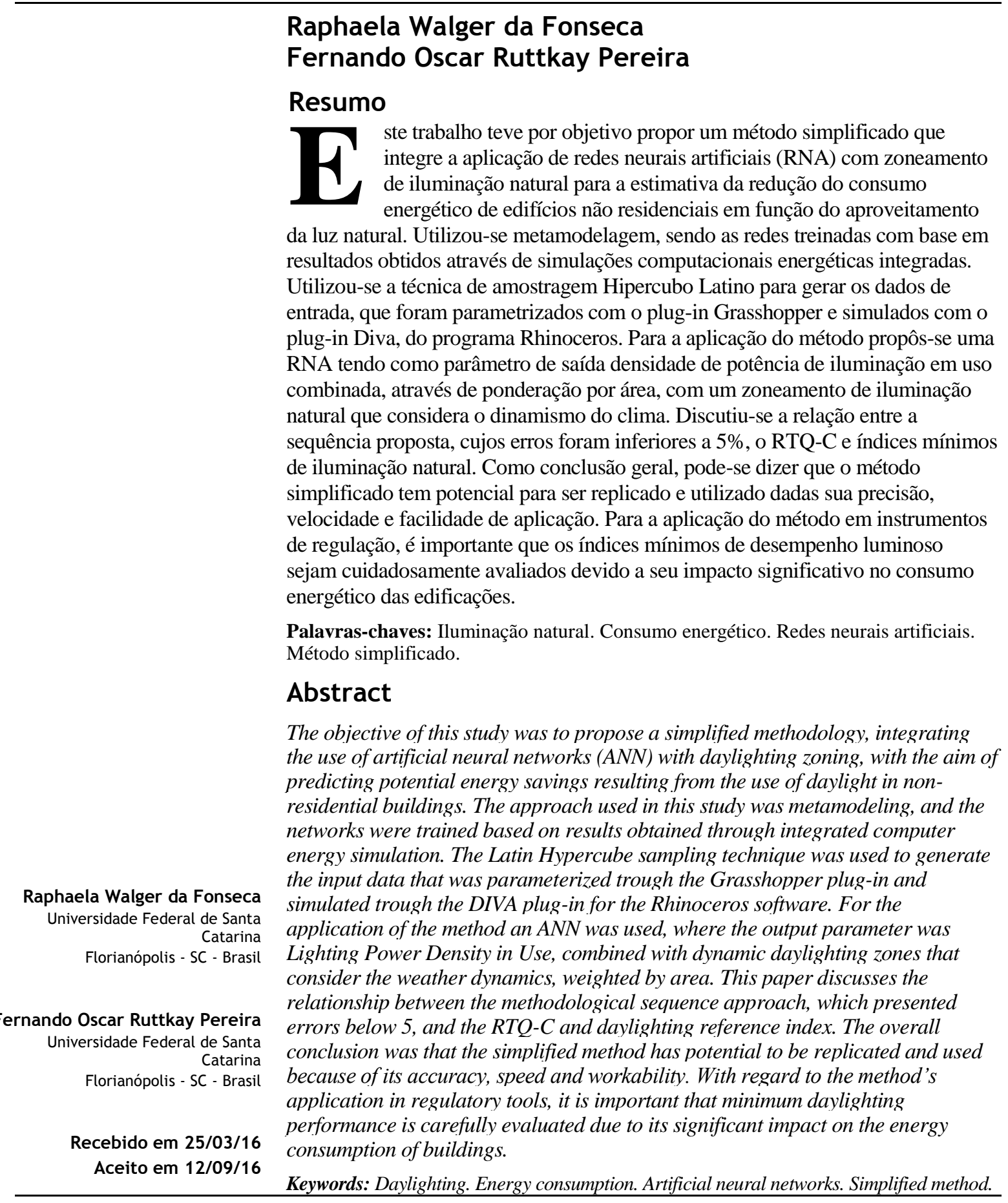

FONSECA, R. W, da; PEREIRA, F. O. R. Sequência metodológica para a estimativa da iluminação natural e suas 55 implicações em sistemas de avaliação de desempenho de edificações. Ambiente Construído, Porto Alegre, v. 17, n. 1, p. 55-68, jan./mar. 2017.

ISSN 1678-8621 Associação Nacional de Tecnologia do Ambiente Construído.

http://dx.doi.org/10.1590/s1678-86212017000100123 


\section{Introdução}

Nos últimos anos, quando se começou a falar mais sistematicamente sobre conservação e uso racional da energia elétrica nos edifícios, o aspecto da integração entre luz natural e artificial passou a ter maior importância. Há um grande número de pesquisas que mostram a preferência pela luz natural como fonte de luz em edifícios (MAYHOUB; CARTER, 2010). Esse fato deve-se a uma série de fatores relacionados com o cumprimento das necessidades biológicas humanas (COMMISSION..., 2003), além do potencial de conservação energética (WILLIAMS et al., 2012).

Assaf e Pereira (2003) definiram a eficiência energética de um sistema de iluminação como a capacidade de um sistema conversor transformar a energia elétrica em condições de visão, conforto e atmosfera visual. Sendo a energia função da potência e do tempo, reduzindo-se uma dessas duas variáveis, reduz-se o consumo energético. $\mathrm{O}$ aproveitamento da iluminação natural está diretamente relacionado à redução do tempo ou da intensidade de acionamento. A eficiência das instalações de iluminação artificial é mais fácil de ser mensurada que as de iluminação natural, pois se trata de um sistema estático. Embora haja discussões sobre a adequabilidade dos indicadores em garantir um ambiente bem iluminado, essa limitação está mais relacionada com a dificuldade de definir e mensurar a qualidade da iluminação. Os mesmos autores propõem um índice que relaciona a eficiência da lâmpada, do equipamento auxiliar, da luminária e do desenho da instalação, e citam mais dois índices: densidade de potência de iluminação (DPI), definido como a potência (W) por unidade de superfície do ambiente iluminado $\left(\mathrm{m}^{2}\right)$; e potência específica de iluminação (PEI), que utiliza a densidade de potência de iluminação necessária para produzir uma iluminância horizontal de 100 lux por unidade de superfície $\left(\mathrm{W} / \mathrm{m}^{2} 100\right.$ lux $)$. O primeiro é utilizado pelas normas americanas ASRHAE/IES 90.1 (ASHRAE, 2013) e TITLE 24 (CALIFORNIA..., 2013) e pelo regulamento brasileiro RTQ-C ${ }^{1}$ (INSTITUTO..., 2010), enquanto o segundo é utilizado pelo código britânico PART-L (ENERGY..., 2014). É importante notar que nenhum desses índices inclui a variável tempo de

${ }^{1}$ O Regulamento Técnico da Qualidade para o Nível de Eficiência Energética de Edifícios Comerciais, de Serviços e Públicos (RTQC), de abrangência nacional, foi publicado na Portaria n. 163, de 8 de junho de 2009, como parte do Programa Brasileiro de Etiquetagem do Instituto Nacional de Metrologia, Qualidade e Tecnologia (Inmetro). Atualmente, a portaria vigente é a de número n. 372, de 17 de setembro de 2010, com três portarias complementares: Portaria n. 17, de 16 de janeiro de 2012; Portaria n. 299, de 19 de junho de 2013; e Portaria n. 126, de 18 de março de 2014. uso, a qual estaria relacionada à iluminação natural. Normalmente esses índices são combinados com algumas considerações sobre sistemas de controles e zoneamento de iluminação natural.

Muitos autores já comprovaram o potencial de aproveitamento da iluminação para a conservação de energia em edifícios comerciais. Em levantamento bibliográfico realizado por Fonseca (2015) foram encontrados percentuais de economia do sistema de iluminação artificial variando entre $20 \%$ e $80 \%$ e entre $12 \%$ e $52 \%$ para o consumo global.

Métodos simplificados de avaliação de iluminação natural são importantes ferramentas idealizadas para serem utilizadas em especial nas fases iniciais de projeto, em que as principais decisões estão sendo tomadas (PEREIRA et al., 2005). Essas ferramentas são idealizadas para dar respostas rápidas sem necessitar significativo detalhamento de informações.

$\mathrm{Na}$ área de eficiência energética em edificações muitas pesquisas relacionadas à elaboração de códigos e normas fazem uso do modelo de regressão linear multivariada (RLM) em suas análises simplificadas; como exemplo no cenário nacional, o RTQ-C (INSTITUTO..., 2010). Entretanto, o uso de regressão não linear multivariada para a aproximação de funções ainda não é muito difundido. As técnicas de regressão não linear multivariada através de redes neurais artificiais (RNA) têm sido utilizadas com boa resposta para modelagens em várias áreas de engenharia devido a sua boa resposta para modelos não lineares (BOCANEGRA, 2002).

As RNA são consideradas um método de inteligência artificial que utiliza técnicas computacionais baseadas em modelos matemáticos, são capazes de aprender e armazenar conhecimento, e são apropriadas para representar ou aproximar sistemas (CARVALHO, 2014; HAYKIN, 2001). Segundo Wong, Wan e Lam (2010), as RNA oferecem melhores respostas para edifícios com os padrões de utilização de energia altamente não lineares, além de melhores correlações e menores erros para a aproximação de funções que outras técnicas como a RLM (BOCANEGRA, 2002). A popularidade das RNA para modelar o desempenho de edifícios tem crescido nas últimas décadas. A exemplo disso, vários trabalhos apresentam um panorama do uso dessa técnica para a modelagem energética de edifícios (KALOGIROU, 2001; KRARTI, 2003 MAGOULÈS; ZHAO; ELIZONDO, 2013). É 
importante ressaltar que apenas 11 anos antes Kalogirou (2001) utilizou alguns poucos exemplos de aplicações de RNA para a predição do consumo energético, enquanto Zhao e Magoulès (2012) apresentaram mais de 50, e Fonseca (2015) 72, apenas três anos depois. Esse crescimento pode ser justificado pelos resultados satisfatórios que essa técnica vem apresentando no campo de estudo. Devido a sua capacidade de modelar relações não lineares as RNA também têm apresentado potencial para modelar desempenho energético considerando a iluminação natural (WONG; WAN; LAM, 2010; FONSECA; DIDONÉ; PEREIRA, 2013). Para avançar na aplicação de RNA em avaliações energéticas, este trabalho propõe um método simplificado que integra o uso de RNA com um zoneamento de iluminação natural para estimar o impacto do aproveitamento da iluminação natural no consumo energético de edificações por meio do parâmetro de desempenho densidade de potência em uso (DPU).

\section{Método}

O método simplificado proposto neste trabalho emprega uma sequência metodológica composta de quatro etapas, que resultam na estimativa de economia de energia do sistema de iluminação atribuída ao aproveitamento da iluminação natural por meio da DPU. A DPU corresponde ao percentual da DPI a ser acionada em função do aproveitamento da luz natural. Para sua determinação propôs-se um índice de redução do uso da densidade de potência instalada ( $\left.\operatorname{IR}_{\mathrm{ILN}}\right)$, seja pela redução do tempo de acionamento, seja pela redução da intensidade mediante a utilização de sensores. Se o $I_{\mathrm{ILN}}$ é $60 \%$, significa que é necessário acionar apenas $60 \%$ da DPI para determinado ambiente em função do aproveitamento da luz natural. A estimativa do $\mathrm{IR}_{\mathrm{ILN}}$ é feita por meio de um metamodelo que utiliza uma RNA baseada em simulações computacionais paramétricas do desempenho energético de uma zona termoluminosa. Os modelos paramétricos foram obtidos por meio da combinação de variáveis-chave da iluminação natural e foram amostrados através da técnica Hipercubo Latino (FONSECA, 2015). Os modelos resultantes foram simulados de forma integrada (Rhinoceros, Grasshoper e DIVA: Daysim e Energyplus) (FELIPPE et al., 2015). Para a proposta do método simplificado o $\operatorname{IR}_{\mathrm{ILN}}$ foi aplicado a um zoneamento de iluminação natural dinâmico que permite estimar a profundidade e a largura das zonas de iluminação natural (FONSECA, 2015).

A sequência metodológica é apresentada por meio de um estudo de caso que tem sua aplicação aprofundada por discussões quanto ao potencial energético do aproveitamento da luz natural ante sistemas de iluminação artificial com diferentes eficiências e quanto a índices mínimos de iluminação natural considerando a satisfação do usuário.

\section{Integração de uma RNA ao zoneamento de iluminação natural}

A integração da RNA com o zoneamento ocorre por meio do $\mathrm{IR}_{\mathrm{ILN}}$ convertido em DPU. Para a determinação da DPU do ambiente todo, o $\mathrm{IR}_{\mathrm{ILN}}$ obtido para cada uma das zonas de iluminação natural e a DPI da zona remanescente (Zona DPI) são ponderados por área.

Com a intenção de que o método simplificado pudesse ser utilizado em ambientes de geometrias variadas e com diferentes quantidades e distribuições de janela, optou-se por vincular a zona e seu respectivo $\mathrm{IR}_{\mathrm{ILN}}$ a uma janela. As zonas de iluminação natural são definidas pela autonomia da luz natural (DA), descrita como o percentual de horas ocupadas em que um nível mínimo de iluminância no plano de trabalho pode ser garantido apenas pela iluminação natural. A Zona 1 foi definida como área em que a iluminânciaalvo é atendida em mais de $50 \%$ das horas do ano (DA $\geq 50 \%$ ), e a Zona 2 , entre $30 \%$ e $50 \%$ das horas do ano $(50 \%>\mathrm{DA} \geq 30 \%)$ (FONSECA, 2015).

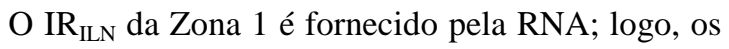
parâmetros de entrada da rede relativos à dimensão da zona correspondem aos obtidos através do zoneamento. $\mathrm{O} \mathrm{IR}_{\mathrm{ILN}}$ da Zona 2 é calculado multiplicando-se o $\mathrm{IR}_{\mathrm{ILN}}$ da Zona 1 pelo fator de ajuste do $\operatorname{IR}_{\mathrm{ILN}}$ para a Zona 2, igual a 1,6 (FONSECA, 2015).

\section{Rede neural artificial}

A RNA utilizada para a estimativa do $\operatorname{IR}_{\mathrm{ILN}}$ foi proposta com base na técnica de validação cruzada multi-fold e definida segundo as seguintes etapas:

(a) normalização dos dados segundo a função de transferência adotada;

(b) determinação do tipo de rede e do algoritmo de treinamento para proceder a sua inicialização; no caso deste estudo foi adotada uma rede Perceptron Multicamadas alimentada adiante com gradiente descendente baseado na retropropagação do erro;

(c) definição do número de neurônios na camada intermediária, determinados através de testes; e 
(d) determinação das funções de transferência, tendo sido adotada a função logarítmica sigmoidal $\left(\operatorname{logsig}^{2}\right)$.

Os parâmetros de treinamento da rede, tais como gradiente mínimo ${ }^{3}$, número máximo de épocas ${ }^{4}$, erro final desejado e taxa de aprendizado ${ }^{5}$, foram definidos segundo a bibliografia e a experimentação. Para a utilização da validação cruzada, o conjunto de dados é dividido em dois subconjuntos. O primeiro é o subconjunto de treinamento e consiste nos exemplos apresentados à rede; e o segundo é o subconjunto teste. $\mathrm{O}$ subconjunto teste tem $10 \%$ a $20 \%$ do conjunto de treinamento; no caso deste trabalho foram adotados $10 \%$. O conjunto original de dados de $\mathrm{N}$ exemplos é, então, dividido em $\mathrm{K}$ subconjuntos, onde $\mathrm{K}$ maior do que 1 . O treinamento do modelo ocorre em todos os subconjuntos, exceto em um, e o erro de validação é medido testando-o sobre o subconjunto previamente separado. O procedimento descrito é repetido por $\mathrm{K}$ tentativas, cada vez utilizando um subconjunto de teste diferente (HAYKIN, 2001).

A seleção de dados para cada subconjunto é feita de forma randômica. Para o presente trabalho foram realizadas dez tentativas $(\mathrm{K})$. As simulações foram feitas no programa Matlab (MATHWORKS..., 2011), do qual foram obtidos os coeficientes de correlação (R) e de determinação $\left(\mathrm{R}^{2}\right)$ de cada uma das dez configurações do subconjunto de treinamento, e os erros absoluto médio (EAM), quadrático médio (EQM) e percentual médio (EPAM) de cada um dos dez subconjuntos de teste. Com isso foi possível averiguar a capacidade da rede em predizer resultados. A rede escolhida para o estudo de caso foi a que apresentou melhor correlação e menores erros.

\section{Zoneamento de iluminação natural}

O zoneamento de iluminação natural de Fonseca (2015), adotado nesta sequência metodológica, abrange equações para a determinação da profundidade e da largura das zonas, como explanado a seguir.

\footnotetext{
${ }^{2}$ Logsig: função de transferência logarítmica sigmoidal do Matlab. Calcula o valor da saída do neurônio a partir das entradas do net, ou seja, o valor que será transferido para a próxima camada, utilizando uma função logarítmica sigmoidal que varia entre 0 e +1 . Tem formato de "S" e é uma função não linear.

${ }^{3}$ Gradiente mínimo de descida: determina um vetor de pesos que minimiza o erro; o parâmetro gradiente mínimo estabelece o desempenho mínimo desse gradiente.

4Épocas: número de interações para o treinamento.

${ }^{5}$ Taxa de aprendizado: geralmente varia entre 0,1 e 1 . Quanto mais baixo for seu valor, mais lento será o aprendizado.
}

A profundidade é calculada utilizando-se uma das 16 equações disponíveis em Fonseca (2015), 8 para a Zona 1, e 8 para a Zona 2, metade delas para iluminância-alvo de 500 lux e a outra metade para 300 lux. Cada equação refere-se a um percentual de abertura da fachada (PAF) diferente, havendo equações para PAF $80 \%, 60 \%$, $40 \%$ e $20 \%$. Essas equações utilizam regressão exponencial multivariada baseada em simulação computacional e consideram a área das superfícies da zona, transmissão visível do vidro $\left(\mathrm{T}_{\mathrm{VIS}}\right)$, refletância média das superfícies $\left(\mathrm{R}_{\text {média }}\right)$, orientação (ORIENT) e fator de obstrução. $O$ fator de obstrução não aparece nas equações, pois é considerado constante e igual a 1 e equivale a uma visão obstruída em $50 \%$ ou menos (O'CONNOR et al., 1997). A refletância média das superfícies é obtida através da ponderação de todas as superfícies do ambiente. Os modelos simulados tanto para o zoneamento quanto para a RNA possuem janelas em fita. Logo, nesta etapa a zona deve ser considerada como se tivesse a largura da janela, e será chamada de "zona da janela". A variável dependente dessas equações é a "área da zona da janela", que é transformada em profundidade considerando-se a zona um paralelepípedo retângulo. Neste artigo as equações serão apresentadas tendo a profundidade como variável dependente.

Para a definição da largura das zonas aplica-se uma equação analítica, a Equação 1, que relaciona a altura da verga com a largura da janela e a largura da zona para um lado da aresta da janela. As equações foram propostas considerando-se as mesmas iluminâncias-alvo e as mesmas autonomias da luz natural que as equações que determinam a profundidade do ambiente. As equações adotam uma constante, o índice de largura de zona $\left(i_{\mathrm{LZ}}\right)$, que varia conforme a iluminância-alvo e o DA solicitado, e podem ser obtidas em Fonseca (2015).

$L_{\text {ZONA }}=\left(H_{V E R G A} * L_{J A N E L A}\right) * i_{L Z}$

Eq. 1

Onde:

$\mathrm{L}_{\text {zona }}$ : largura da zona para cada lado a partir da aresta da janela (m);

$\mathrm{H}_{\text {verga }}$ : altura da verga em relação ao piso $(\mathrm{m})$;

$\mathrm{L}_{\text {janela: }}$ largura da janela em si (m); e

$\mathrm{i}_{\text {LZ: }}$ índice de largura de zona (adimensional).

A área de cada zona é o produto de sua largura por sua profundidade. Para o cálculo da área da Zona 2 desconta-se a área da Zona 1, pois são coincidentes. 


\section{Sequência metodológica}

A sequência metodológica é apresentada na forma de um estudo de caso. Foi considerado um ambiente de $5,20 \mathrm{~m}$ por $6,65 \mathrm{~m}$, com pé-direito de $3,00 \mathrm{~m}$ e a altura da verga de $2,40 \mathrm{~m}$. A única janela do ambiente, uma porta-janela com vidro simples, denominada Janela 1 , tem $2,25 \mathrm{~m}$ de largura e foi centralizada na maior dimensão do ambiente a orientação leste. Como refletância das superfícies, utilizaram-se $20 \%, 40 \%$ e $80 \%$ para piso, parede e teto respectivamente. Estipulou-se atividade de escritório com iluminância-alvo de 500 lux e DPI classe A do RTQ-C pelo método da área do edifício igual a $9,7 \mathrm{~W} / \mathrm{m}^{2}$.

A sequência é apresentada em quatro passos:

(a) $1^{\circ}$ PASSO: definição da profundidade das zonas:

- determina-se a iluminância-alvo e calcula-se o PAF da "zona da janela";

- selecionam-se as equações para o cálculo da profundidade da Zona 1 e da Zona 2 entre as 16 equações para zoneamento dinâmico de Fonseca (2015), conforme a iluminância-alvo e o PAF; e

- levantam-se os demais valores das variáveis do ambiente e aplica-se a equação selecionada.

(b) $2^{\circ}$ PASSO: definição da largura das zonas:

- calcula-se a largura das zonas para cada lado a partir da aresta da janela $\left(\mathrm{L}_{\mathrm{ZONA}}\right)$, aplicando-se a equação analítica de Fonseca (2015), Equação 1; e

- soma-se a largura da janela à L Lona. Limita-se a largura da zona a eventuais obstáculos físicos que impeçam a distribuição da luz. (c) $3^{\circ}$ PASSO: cálculo do $\mathrm{IR}_{\mathrm{ILN}}$ das zonas:

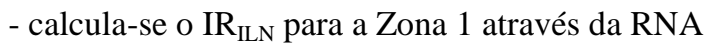
utilizando-se os dados de descrição da zona como valores de entrada; e

- calcula-se o IR $\mathrm{IR}_{\mathrm{ILN}}$ da Zona 2 multiplicando-se o valor de $\mathrm{IR}_{\mathrm{ILN}}$ obtido para a Zona 1 pelo fator de ajuste de $\mathrm{IR}_{\mathrm{ILN}}$ para a Zona $2\left(\mathrm{FA}_{\mathrm{DPU}}\right)$, igual a 1,6 (FONSECA, 2015), ver Equação 2.

A Tabela 1 ilustra os valores deste estudo de caso.

$I R_{I L N_{Z} Z Z}=I R_{I L N_{-} Z 1} * F A_{D P U}$

Eq. 2

Onde:

$\mathrm{IR}_{\mathrm{ILN}} \mathrm{Z} 1$ : índice de redução do uso da densidade de potência instalada em função da iluminação natural para a Zona $1\left(\%_{\text {DPI }}\right)$;

$\mathrm{IR}_{\mathrm{ILN} Z \mathrm{Z2}}$ : índice de redução do uso da densidade de potência instalada em função da iluminação natural para a Zona $2\left(\%_{\text {DPI }}\right)$; e

$\mathrm{FA}_{\mathrm{DPU}}$ : fator de ajuste de $\mathrm{IR}_{\mathrm{ILN}}$ para a Zona 2 (adimensional).

(d) $4^{\circ}$ PASSO: cálculo da DPU do ambiente:

- calcula-se a área da Zona 1, da Zona 2 e da Zona DPI;

- obtém-se o $\operatorname{IR}_{\mathrm{ILN}}$ do ambiente através da ponderação do $\operatorname{IR}_{\mathrm{ILN}}$ da Zona 1 , Zona 2 e Zona DPI por suas respectivas áreas. $\mathrm{O} \mathrm{IR}_{\mathrm{ILN}}$ da Zona DPI é $100 \%$, ou seja, DPI acionada em $100 \%$ das horas de ocupação com $100 \%$ de intensidade; e

- calcula-se a DPU do ambiente multiplicando-se o $\mathrm{IR}_{\mathrm{ILN}}$ do ambiente pela DPI dele.

Tabela 1 - Dado de entrada da Zona 1 (zona da janela) utilizado na RNA

\begin{tabular}{|c|c|c|c|}
\hline VARIÁVEL & VALOR ADOTADO & VARIÁVEL & VALOR ADOTADO \\
\hline Refletância teto (\%) & 80 & DCI_pessoas (W/pessoa) & 0,53 \\
\hline Refletância parede (\%) & 40 & \multirow{3}{*}{$\begin{array}{l}\text { Propriedades térmicas } \\
\text { (pouca troca e } \\
\text { absortância constante) } \\
\text { (código) }\end{array}$} & \multirow{3}{*}{2} \\
\hline PAF (\%) & 80 & & \\
\hline PAZ $(\%)$ & 0 & & \\
\hline PAZ: abertura única (binário) & 0 & Largura $(\mathrm{m})$ & 2,96 \\
\hline $\begin{array}{l}\text { PAZ: abertura distribuída } \\
\text { (binário) }\end{array}$ & 0 & Profundidade (m) & 3,63 \\
\hline Proteção solar horizontal $\left({ }^{\circ}\right)$ & 0 & Altura (m) & 3,00 \\
\hline Proteção solar vertical $\left(^{\circ}\right)$ & 0 & Ocupação (m²/pessoa) & 12 \\
\hline $\mathrm{T}_{\mathrm{VIS}}$ & 0,88 & Ângulo de obstrução $\left(^{\circ}\right)$ & 0 \\
\hline FS & 0,82 & $\begin{array}{l}\text { Influência do piso } \\
\text { externo }\end{array}$ & 0 \\
\hline Orientação $\left(^{\circ}\right)$ & 90 & $\mathrm{DPI}\left(\mathrm{W} / \mathrm{m}^{2}\right)$ & 9,7 \\
\hline DCI_equipamentos $\left(\mathrm{W} / \mathrm{m}^{2}\right)$ & 15 & Iluminância-alvo (lux) & 500 \\
\hline
\end{tabular}




\section{Verificação do erro da proposta apresentada}

Foram feitas três verificações para a análise dos erros inerentes à aplicação conjunta do metamodelo com os modelos de regressão exponencial do zoneamento:

(a) verificação do erro das equações de zoneamento dinâmico utilizadas no estudo de caso;

(b) comparação do resultado previsto pela RNA com o resultado da simulação termoenergética integrada para a Zona 1; e

(c) comparação do resultado do método simplificado com o resultado simulado para o ambiente todo.

\section{Impacto do aproveitamento da iluminação natural na classificação de eficiência energética}

Para avaliar o impacto da iluminação natural em avaliações de eficiência energética, o resultado da DPU do estudo de caso foi comparado a resultados obtidos por Scalco et al. (2015). No referido estudo os autores investigaram o impacto de um retrofit do sistema de iluminação em doze edifícios de escritórios. Sistemas de iluminação classe D (DPI de $14,1 \mathrm{~W} / \mathrm{m}^{2}$ ), segundo o método da área do edifício da etiqueta PBE Edifica, foram substituídos por sistemas classe A (DPI de 9,7 $\mathrm{W} / \mathrm{m}^{2}$ ) e por um sistema de LED com DPI de 5,4 $\mathrm{W} / \mathrm{m}^{2}$, baseado em um valor médio para sistemas de LED eficientes obtidos na bibliografia.

A comparação foi feita de forma gráfica em valores percentuais e visou avaliar o potencial de economia de energia em $\mathrm{kWh} / \mathrm{m}^{2}$.ano e o impacto na classificação de eficiência energética segundo a etiqueta PBE Edifica.

\section{Índices mínimos de iluminação natural visando à eficiência energética de acordo com as preferências do usuário}

Para discutir a adequabilidade dos níveis mínimos de iluminação natural, o zoneamento adotado neste estudo foi sobreposto ao diagrama para determinação da suficiência de iluminação natural proposto por Heshong (2011).

O diagrama foi feito com base em equações de regressão, relacionando a preferência dos ocupantes com a área dos ambientes considerada suficientemente iluminada e o tempo que essa iluminação poderia ser garantida apenas com iluminação natural. Esse conceito é denominado autonomia da luz natural espacial (sDA). Para avaliar a suficiência de acordo com a preferência dos usuários adotou-se como critério o percentual da área dos ambientes que atingisse ou ultrapassasse o limite de 300 lux por X\% de tempo em $75 \%$ dos pontos do ambiente. Para isso foi utilizada uma escala de desejabilidade (Likert scale), empregada pelos entrevistados para expressar sua satisfação com o ambiente luminoso (HESHONG, 2011).

Para relacionar o estudo de caso com o diagrama em questão, primeiramente calculou-se o sDA para a Zona 1 e para a Zona 2. Visto que o estudo de caso utiliza uma iluminância-alvo de 500 lux e o diagrama em questão é baseado em uma iluminância-alvo de 300 lux, aplicaram-se novamente os dois primeiros passos da sequência metodológica para o mesmo ambiente considerando-se esta iluminância. Por fim, calculou-se o consumo de cada faixa de desejabilidade do diagrama de Heshong (2011) para cada um dos três sistemas de iluminação de Scalco et al. (2015), considerando-se o ambiente ocupado $8 \mathrm{~h}$ por dia em 260 dias do ano.

\section{Resultados}

\section{Sequência para determinação da DPU do ambiente}

Primeiramente é apresentado o resultado do treinamento da RNA escolhida para o estudo de caso e em seguida os resultados do mesmo.

\section{Rede neural artificial}

Comparou-se o desempenho das dez RNA treinadas e a RNA 9 foi a que apresentou correlação mais forte e menores erros. Todas as redes tiveram seu desempenho avaliado nos conjuntos de treinamento, de teste e para a "zona da janela" do estudo de caso. Os resultados de desempenho obtidos para a RNA 9 são apresentados na Tabela 2 .

\section{Sequência metodológica}

$1^{\circ}$ passo: definição da profundidade das zonas

Para o cálculo do PAF, a área de fachada foi considerada o produto entre o pé-direito do ambiente (3,00 m) e a largura da Janela $1(2,25 \mathrm{~m})$, resultando em $6,75 \mathrm{~m}^{2}$. A área da Janela 1 diferencia-se da área da fachada apenas pelo desconto da altura da verga em relação à altura do pé-direito, resultando em $5,4 \mathrm{~m}^{2}$, logo PAF $80 \%$. Selecionaram-se as equações de Fonseca (2015) para o referido PAF e para a iluminância de 500 
lux. Essas equações foram aqui apresentadas como Equação 3, para a Zona 1, e como Equação 4, para a Zona 2.

$$
\operatorname{Prof} f_{Z O N A}=\frac{\operatorname{EXP}\left[\begin{array}{c}
\left(1,3224 * T_{V I S}\right)+(0,0005 * \text { ORIENT }) \\
+\left(178,0858 * \frac{1}{D A_{50 \%}}\right)+ \\
\left(0,0019 * \frac{1}{(1-R)}\right)
\end{array}\right]}{\operatorname{EXP}\left[\begin{array}{c}
\left(1,3364 * T_{V I S}\right)+(0,0004 * \text { ORIENT }) \\
+\left(113,3528 * \frac{1}{D A_{30 \%}}\right)+ \\
\left(0,0015 * \frac{1}{(1-R)}\right)
\end{array}\right]} \text { Eq. } 3
$$

Onde:

Prof $_{\text {zona }}$ : profundidade da zona (m);

$\mathrm{T}_{\mathrm{VIS}}$ : transmissão visível (\%);

ORIENT: orientação da abertura $\left(^{\circ}\right)$;

$\mathrm{DA}_{\text {alvo }}$ : autonomia da luz natural mínima a ser obtida na zona-alvo (\%);

$\mathrm{R}_{\text {média: }}$ : refletância média de todas as superfícies do ambiente ponderadas pelas respectivas áreas (\%);

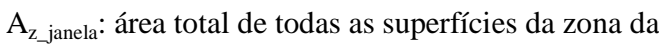
janela $\left(\mathrm{m}^{2}\right)$;

$\mathrm{L}_{\text {zona }}$ : largura da zona $(\mathrm{m})$; e

$\mathrm{H}_{\text {zona: }}$ altura da zona (pé-direito útil) (m).

Os demais dados do ambiente deste estudo de caso necessários à aplicação das equações foram compilados na Tabela 3.
Como resultado da aplicação da Equação 3, a Zona 1 ficou com 2,96 m de profundidade; e, como resultado da aplicação da Equação 4, a Zona 2 ficou com 4,02 $\mathrm{m}$ de profundidade.

\section{$2^{\circ}$ passo: definição da largura das zonas}

Aplicando-se os dados apresentados na Tabela 4 à Equação 1 obteve-se uma largura de zona medida a partir da aresta da janela $\left(\mathrm{L}_{\mathrm{ZONA}}\right)$ de $0,69 \mathrm{~m}$ para a Zona 1 e de 1,22 m para a Zona 2.

Devido à ausência de obstáculos físicos perpendiculares à janela que impedissem a distribuição da luz, a $\mathrm{L}_{\text {ZONA }}$ foi aplicada às duas arestas dela. A soma da largura real da janela com as respectivas $\mathrm{L}_{\mathrm{ZONA}}$ resultou em uma largura total de 3,63 m para a Zona 1 e de $4,17 \mathrm{~m}$ para a Zona 2. O resultado do zoneamento pode ser visto na Figura 1.

\section{$3^{\circ}$ passo: cálculo do $\operatorname{IR}_{\mathrm{ILN}}$ das zonas}

Aplicaram-se os dados de entrada do ambiente apresentados na Tabela 1 à RNA 9, que retornou um $\operatorname{IR}_{\text {ILN }}$ de $6,28 \% \%_{\text {DPI. }}$.

Para a determinação do $\mathrm{IR}_{\mathrm{ILN}}$ da Zona 2 aplicou-se o fator de ajuste de $\mathrm{IR}_{\mathrm{ILN}}$ para a Zona $2\left(\mathrm{FA}_{\mathrm{DPU}}\right)$ (FONSECA, 2015) ao $\mathrm{IR}_{\mathrm{ILN}}$ da Zona 1 por meio da Equação 2, obtendo-se um IR $\mathrm{ILN}_{\mathrm{ILN}}$ de $10,04 \%_{\mathrm{DPI}}$.

\section{$4^{0}$ passo: cálculo da DPU do ambiente}

A Tabela 5 ilustra as áreas da Zona 1, da Zona 2 e

\begin{tabular}{|c|c|c|c|c|c|c|c|}
\hline \multicolumn{2}{|c|}{$\begin{array}{l}\text { Referente ao } \\
\text { treinamento }\end{array}$} & \multicolumn{2}{|c|}{$\begin{array}{c}\text { Conjunto de treinamento } \\
\text { simulado pela rede }\end{array}$} & \multicolumn{2}{|c|}{ Conjunto de teste } & \multicolumn{2}{|c|}{ "Zona da janela" } \\
\hline $\mathrm{R}^{2}$ & 0,9801 & EAM (\% $\left.\%_{\text {DPI }}\right)$ & 3,28 & EAM (\% $\left.\%_{\text {DPI }}\right)$ & 4,13 & $\operatorname{EAM}\left(\%_{\mathrm{DPI}}\right)$ & 0,50 \\
\hline $\mathrm{R}$ & 0,9892 & DesvPad EAM & 2,72 & DesvPad EAM & 4,76 & EPAM (\%) & 7,41 \\
\hline EAMN & 0,03 & $\mathrm{EQM}\left(\%_{\mathrm{DPI}}\right)$ & 4,26 & EQM (\% $\left.\%_{\mathrm{DPI}}\right)$ & 6,29 & & \\
\hline EQMN & 0,04 & EPAM $(\%)$ & 8,36 & EPAM $(\%)$ & 9,05 & & \\
\hline
\end{tabular}
da Zona DPI e seus respectivos IR $_{\text {ILN }}$ utilizados para a ponderação do $\mathrm{IR}_{\mathrm{ILN}}$ do ambiente.

Tabela 2 - Desempenho da RNA 9

Tabela 3 - Dados de entrada para as equações da profundidade das zonas

\begin{tabular}{c|c|c|c|c|c|c}
\hline ZONA & $\begin{array}{c}\text { PAF } \\
(\boldsymbol{\%})\end{array}$ & $\begin{array}{c}\text { Iluminância-alvo } \\
\text { (lux) }\end{array}$ & $\mathbf{T}_{\text {vis }}$ & $\begin{array}{c}\text { ORIENTAÇÃO } \\
(\mathbf{(})\end{array}$ & DA $_{\text {MIN }}(\boldsymbol{\%})$ & $\mathbf{R}_{\text {média }}$ \\
\hline Z1 (DA 50\%) & 80 & 500 & $0,80(80 \%)$ & 90 & 50 & $0,44(44 \%)$ \\
Z2 (DA 30\%) & 80 & 500 & $0,80(80 \%)$ & 90 & 30 & $0,44(44 \%)$ \\
\hline
\end{tabular}

Tabela 4 - Dados de entrada utilizados para as equações da determinação da largura das zonas Z1 e Z2

\begin{tabular}{c|c|c|c|c}
\hline ZONA & $\mathbf{H}_{\text {verga }}(\mathbf{m})$ & $\mathbf{L}_{\text {janela }}(\mathbf{m})$ & $\mathbf{H}_{\text {verga }} * \mathbf{L}_{\text {janela }}\left(\mathbf{m}^{2}\right)$ & $\mathbf{i}_{\text {LZ }}$ \\
\hline Z1 (DA 50\%) & 2,40 & 2,25 & 5,40 & 0,1281 \\
Z2 (DA 30\%) & 2,40 & 2,25 & 5,40 & 0,2265 \\
\hline
\end{tabular}


Figura 1 - Aplicação do zoneamento

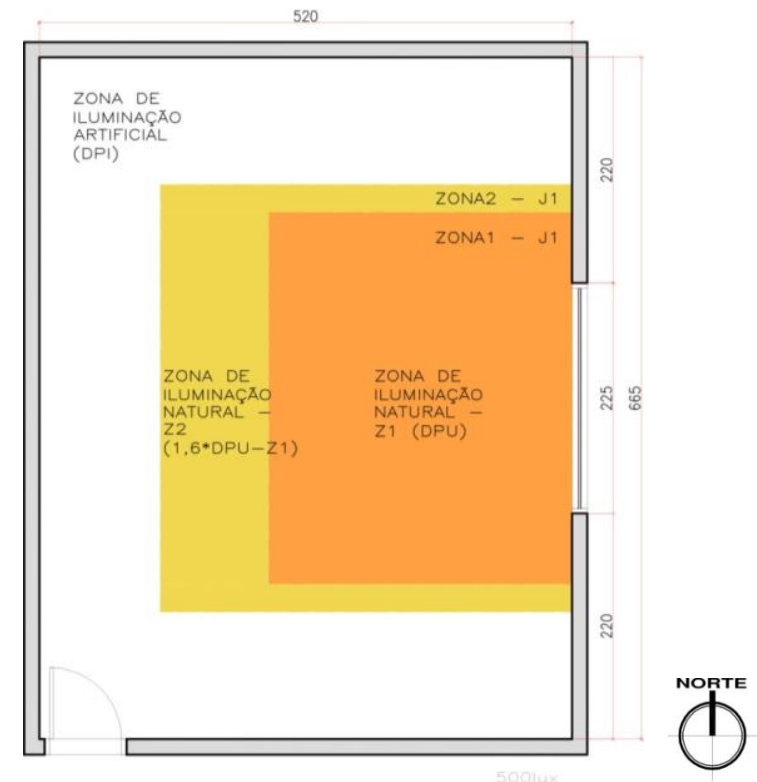

Tabela 5 - Ponderação dos $\mathbf{I R}_{\mathrm{ILN}}$ pelas respectivas áreas das zonas

\begin{tabular}{l|c|c}
\hline & Área $\left(\mathbf{m}^{2}\right)$ & IR $_{\text {ILN }}\left(\%_{\text {DPI }}\right)$ \\
\hline Área total do ambiente & 34,58 & \\
Zona 1 & 10,74 & 6,28 \\
Zona 2 (descontando-se a sobreposição da Zona 1) & 6,01 & 10,04 \\
Zona DPI & 17,83 & 100 \\
\hline Ponderação: IR ILN $_{\text {ambiente }}$ & 55,25 \\
\hline
\end{tabular}

Como resultado, esse ambiente requer apenas $55,25 \%$ da DPI acionada nas horas ocupadas. Aplicando-se esse percentual à DPI do ambiente, $9,70 \mathrm{~W} / \mathrm{m}^{2}$, a DPU resulta em $5,36 \mathrm{~W} / \mathrm{m}^{2}$.

\section{Verificação do erro da proposta apresentada}

O resultado do desempenho do zoneamento dinâmico representado pela Equação 3 e pela Equação 4 foi apresentado na Tabela 6. Ambas as equações erraram suas previsões em cerca de $12 \%$.

$\mathrm{O}$ resultado do $\mathrm{IR}_{\mathrm{ILN}}$ para a Zona 1 previsto pela rede neural apresentou erro absoluto de $0,50 \%$ DPI $\mathrm{e}$ erro percentual médio de $7,42 \%$. Os valores de IR $_{\text {ILN }}$ obtidos através da RNA 9 e da simulação termoenergética integrada são apresentados na Tabela 7.

Comparando o resultado da aplicação do método simplificado com a simulação do ambiente todo, o erro percentual médio foi de $4,24 \%$, como pode ser visto na Tabela 8 .

\section{Impacto do aproveitamento da iluminação natural na classificação de eficiência energética}

A redução do consumo do sistema de iluminação obtida por Scalco et al. (2015) na substituição da DPI D pela DPI A foi de $31,2 \%$, enquanto por LED foi de $61,7 \%$. Ao considerar a DPU do estudo de caso, resultante da mesma DPI A adotada por Scalco et al. (2015) somada à iluminação natural, o retrofit reduziria o consumo de iluminação em 62,0\%. A Figura 2 ilustra essa comparação para dois edifícios avaliados por Scalco et al. (2015), o que apresentou menor e o que apresentou maior variação de consumo devido ao retrofit. Nesta figura a barra cinza indica o resultado referente ao uso da DPU do estudo de caso (DPI A com iluminação natural). A DPI A combinada com a iluminação natural apresentou diferença percentual absoluta de 30,8\% em relação à classe A e 0,3\% em relação ao LED. Em unidade de consumo, o sistema de iluminação classe D consumiria 45,6 $\mathrm{kWh} / \mathrm{m}^{2}$.ano; o classe A, $31,4 \mathrm{kWh} / \mathrm{m}^{2}$.ano; a opção com LED, $17,5 \mathrm{kWh} / \mathrm{m}^{2}$.ano; e a DPI A combinada com a iluminação natural, 17,3 $\mathrm{kWh} / \mathrm{m}^{2}$.ano. 
Tabela 6 - Desempenho das equações

\begin{tabular}{c|c|c}
\hline & \multicolumn{3}{c}{ ERROS INERENTES ÀS EQUAÇÕES } \\
\hline & Equação Z1 500 lux PAF 80\% & Equação Z1 e Z2 500 lux PAF 80\% \\
& $(\mathbf{D A} \geq \mathbf{5 0 \% )}$ & $\mathbf{( 3 0 \%} \geq \mathbf{D A}>\mathbf{5 0 \% )}$ \\
\hline $\mathbf{R}^{2}$ & 0,9990 & 0,9990 \\
$\operatorname{EQM}\left(\mathbf{m}^{2}\right)$ & 0,65 & 0,66 \\
$\operatorname{EPAM}(\boldsymbol{\%})$ & 12,04 & 12,24 \\
\hline
\end{tabular}

Tabela 7 - IR $\mathbb{R}_{\mathrm{ILN}}$ para a Zona 1 estimado pela RNA 9 e simulado pelo plug-in DIVA

\begin{tabular}{c|c|c}
\hline & $\begin{array}{c}\text { Valor estimado pela } \\
\text { RNA 9 }-\mathbf{I R}_{\mathbf{I L N}}\left(\%_{\text {DPI }}\right)\end{array}$ & $\begin{array}{c}\text { Valor simulado - } \\
\mathbf{I R}_{\mathbf{I L N}}\left(\%_{\text {DPI }}\right)\end{array}$ \\
\hline $\mathbf{I R}_{\mathbf{I L N}}$ & 6,28 & 6,78 \\
\hline
\end{tabular}

Tabela 8 - Comparação do $\mathbb{I R}_{\mathrm{ILN}}$ estimado pelo método simplificado e por simulação considerando todo o ambiente

\begin{tabular}{c|c|c|c}
\hline $\begin{array}{c}\text { IR }_{\text {ILN }} \text { : Método } \\
\text { simplificado } \\
\left(\%_{\text {DPI }}\right)\end{array}$ & $\begin{array}{c}\text { IR }_{\text {ILN }}: \\
\text { Simulação } \\
\text { DIVA }\left(\%_{\text {DPI }}\right)\end{array}$ & $\begin{array}{c}\text { EAM do método } \\
\text { simplificado } \\
\left(\%_{\mathrm{DP}} \mathrm{I}\right)\end{array}$ & $\begin{array}{c}\text { EPAM do método } \\
\text { simplificado } \\
(\% \text { de erro })\end{array}$ \\
\hline 55,25 & 57,70 & 2,45 & 4,24 \\
\hline
\end{tabular}

A Figura 2 destaca a variação $(\Delta)$ da redução de consumo total e do sistema de condicionamento de ar para as duas opções de retrofit de forma a ilustrar o potencial adicional de economia não verificado para a opção com iluminação natural. Destaca-se que o controle do sistema de iluminação artificial em função da luz natural não apresenta nenhuma alteração na admissão de carga térmica externa para a edificação, visto que a simulação já computa o efeito da radiação. A única diferença é que o sistema de iluminação artificial seria acionado com um padrão de uso menos intenso (tempo ou potência) e, em consequência, reduziria a geração de carga térmica interna.

Quanto ao impacto na classificação da Etiqueta PBE Edifica, Scalco et al. (2015) obtiveram que, para o retrofit utilizando a DPI A, 10 das 12 edificações $(83 \%)$ passaram de classificação geral D para $\mathrm{C}$, enquanto nas demais a melhoria foi ainda maior, passando de D para B. O retrofit utilizando LED elevou a classificação de 8 edificações $(67 \%)$ de $\mathrm{D}$ para $\mathrm{A}$, enquanto os quatro casos restantes (33\%) passaram de D para B. Logo, diante da comparação dos desempenhos observados na Figura 2, pode-se afirmar que o aproveitamento da iluminação natural permite a elevação de uma a três classes de eficiência energética global da edificação.

\section{Adequabilidade dos níveis de iluminamento de acordo com as preferências do usuário}

A Figura 3 ilustra o diagrama de suficiência da luz natural proposto por Heshong (2011). No eixo das abscissas relaciona-se o percentual do tempo de ocupação, e no das ordenadas o percentual da área em que a iluminância mínima de 300 lux era garantida. A preferência dos usuários foi destacada em escala de cores e classificada conforme a aceitabilidade de determinadas combinações entre o tempo e a área em que o critério de iluminância mínima era atingido. Assim, pode-se perceber que, conforme se aumenta o percentual da área em que essa iluminância mínima é atingida, a exigência quanto ao tempo mínimo torna-se menor.

Considerando-se o parâmetro sDA para as zonas do estudo de caso, ter-se-ia:

- Zona 1 igual a sDA $\mathrm{A}_{500 l u x, 50 \% \text { tempo: }}$ critério atendido em $31,1 \%$ da área do ambiente; e

- Zona 2 igual a sDA $\mathrm{S}_{500 l u x, 30 \% \text { tempo }}$ critério atendido em $40,4 \%$ da área do ambiente.

Aplicando-se o zoneamento para o mesmo ambiente, mas com a iluminância-alvo utilizada no diagrama, 300 lux, poder-se-ia dizer que:

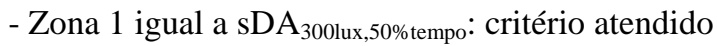
em $67,6 \%$ da área do ambiente; e

- Zona 2 igual a sDA $300 l u x, 30 \%$ tempo: critério atendido em $100 \%$ da área do ambiente. 
Figura 2 - Comparação da DPU do exemplo com os casos de menor e maior impacto de Scalco et al. (2015)

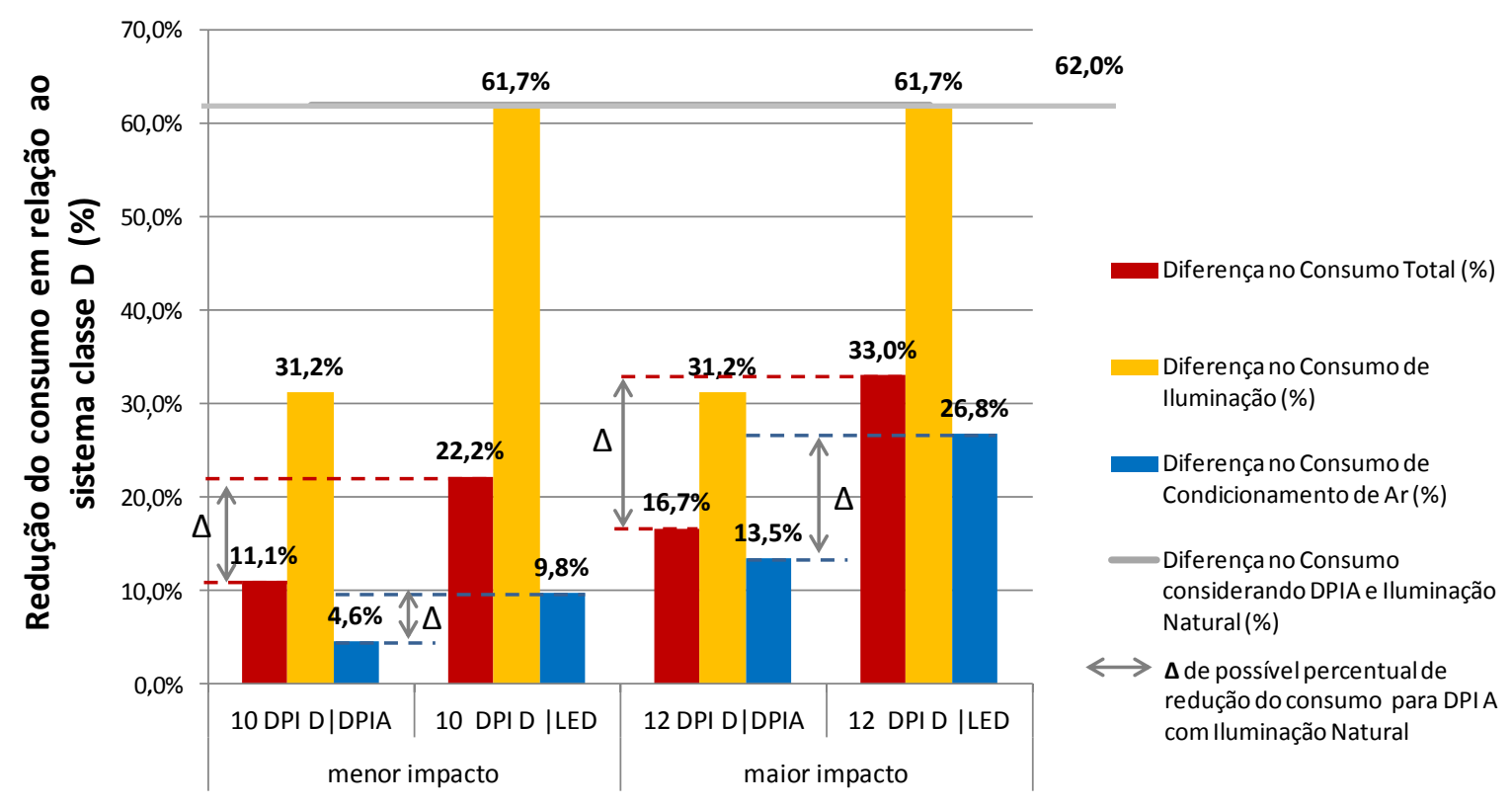

Figura 3 - Diagrama de critérios para definição de adequabilidade da autonomia da luz natural espacial

Diagrama resumo dos resultados da pesquisa de Heschong (2011) segundo escala de desejabilidade (Likert scale) para o percentual da área (X\% dos sensores) em que a iluminância de projeto de 300 lux é alcançada em pelo menos determinada quantidade de tempo ( $\mathrm{\%} \%$ das horas do ano).

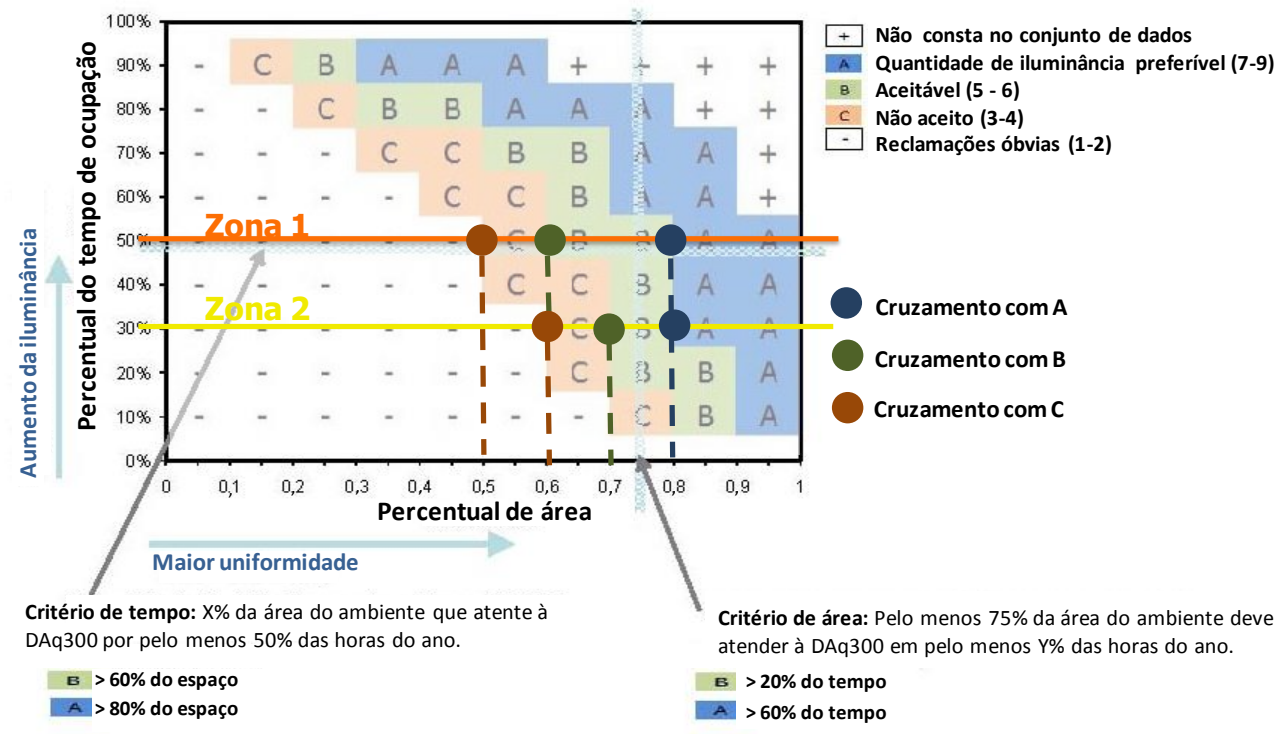

Fonte: adaptado de Heshong (2011).

Transpondo-se esses percentuais para o diagrama da Figura 3, poder-se-ia dizer que o ambiente é suficientemente iluminado, visto que mais de $80 \%$ da área do ambiente alcança 300 lux em $30 \%$ tempo. Esse resultado foi destacado no diagrama através do cruzamento da linha amarela referente à Zona Z2, com a linha pontilhada azul referente ao percentual de área necessária para garantir o mais alto grau de satisfação do usuário (desejabilidade A).

Como ressalva, deve-se assumir que as classificações para as zonas Z1 e Z2 não são comparáveis entre si, visto que a $\mathrm{Z1}$ é mais

64 Fonseca, R. W, da; Pereira, F. O. R. 
restritiva que a $\mathrm{Z} 2$ em termos de horas atendidas. Esse diagrama é apropriado para a definição de "índices mínimos" com relação à preferência do usuário. Como exemplo, dir-se-ia: caso se atenda ao limite da $\mathrm{Z1}\left(\mathrm{DA}_{300,50 \% \text { tempo }}\right)$, para que os usuários estejam satisfeitos em grau $\mathrm{A}, \mathrm{B}$ ou $\mathrm{C}$, a zona deve ocupar um mínimo de $80 \%, 60 \%$ e $50 \%$ da área do ambiente respectivamente. Essa comparação visou salientar a importância da combinação de avaliações do desempenho com as avaliações de conforto do usuário. Nesse caso, a combinação aplicada ao ambiente do estudo de caso complementaria o resultado da avaliação.

A Figura 4 ilustra a variação de consumo conforme a tecnologia e eficiência do sistema de iluminação artificial adotado por Scalco et al. (2015) e as diferentes classes de desejabilidade de Heshong (2011), destacando-se as zonas adotadas neste trabalho. O percentual de tempo de ocupação utilizado para o cálculo do consumo apresentado na Figura 4 considerou os limites das categorias A, B e C de Heshong (2011) para 75\% da área, conforme o cruzamento da linha cheia vertical azul da Figura 3. Heshong (2011), ao final de suas análises, recomendou a adoção de $\mathrm{sDA}_{3001 \mathrm{ux}, 50 \% \text { tempo }}$ em $75 \%$ da área como índice mínimo para garantir a satisfação do usuário. Esses valores foram

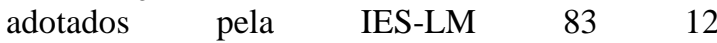
(ILLUMINATING....., 2012), que vem sendo incorporada por sistema de avaliação como o LEED v.4 (U.S. GREEN..., 2014). Por meio dessa comparação, pode-se verificar que a alteração do critério de índice mínimo poderia refletir em uma variação de consumo de até 91,8\% para DPI classe A do RTQ-C (INSTITUTO..., 2010), por exemplo. Vale destacar que um ambiente bem projetado que garanta o atendimento à faixa de desejabilidade $\mathrm{A}$ com iluminação natural, precisará de menor quantidade complementar de iluminação artificial independente da eficácia luminosa do sistema, como pode ser observado na Figura 4. Ao se comparar o consumo de iluminação do cenário de baixo aproveitamento da luz natural (desejabilidade C) complementado por tecnologia ineficiente de iluminação artificial (DPI D) a um cenário propício ao aproveitamento da luz natural (desejabilidade A) utilizando tecnologia eficiente (DPI LED), observou-se que o consumo do segundo cenário foi 13 vezes menor do que o do primeiro. Acrescenta-se ainda o potencial de ganhos devido aos demais benefícios atribuídos ao rendimento e a saúde de um usuário satisteito com um ambiente bem iluminado naturalmente.

\section{Discussão}

A sequência metodológica abordada neste trabalho suscitou a discussão de sua aplicabilidade, da relevância da luz natural em avaliações energéticas e do impacto de diferentes índices mínimos para averiguar a suficiência de luz. Quanto à aplicabilidade, ao considerar diferentes iluminâncias-alvo, a sequência metodológica permite que projetistas avaliem espaços com diferentes usos e necessidades de iluminamento. $\mathrm{O}$ zoneamento dinâmico de iluminação natural ainda pode ser útil como apoio ao projeto luminotécnico para a locação de sensores de iluminação natural e a divisão dos circuitos de iluminação artificial.

Quanto à proposição da RNA baseada no $\mathrm{IR}_{\mathrm{ILN}}$, ressalta-se que, apesar de esse parâmetro ser relacionado apenas ao sistema de iluminação artificial, ele pode ser utilizado em combinação com outros métodos para gerar informação sobre o impacto no balanço térmico da edificação. Uma aplicação é utilizar a DPU como dado de entrada para a simulação termoenergética integrada em substituição à DPI como alternativa à simulação integrada. Isso pode ser feito tanto em simulações detalhadas quanto em simulações simplificadas, a exemplo das várias interfaces do programa EnergyPlus (UNITED..., 2012). Além de dado de entrada para a simulação computacional, pode servir como dado de entrada para outros métodos simplificados destinados à previsão do desempenho térmico da edificação que considerem a influência da densidade de potência instalada de iluminação.

Outro possível uso do método é a complementação do Regulamento Técnico da Qualidade de Edificações Comerciais, de Serviços e Públicas (RTQ-C) (INSTITUTO..., 2010). Para computar o aproveitamento da luz natural, os valores de DPI e DPU de cada ambiente devem ser ponderados por suas respectivas áreas. O resultado dessa ponderação é inserido no termo referente à avaliação do sistema de iluminação artificial da Equação da Pontuação Final do mesmo regulamento (Equação 5).

$$
\begin{aligned}
& P T=0,30 *\left[\left(E q N u m E n v * \frac{A C}{A U}\right)+\left(\frac{A P T}{A U} * 5+\frac{A N C}{A U} *\right.\right. \\
& E q N u m V)]+0,30 *(E q N u m D P I)+0,4 * \\
& {\left[\left(E q N u m A C * \frac{A C}{A U}\right)+\left(\frac{A P T}{A U} * 5+\frac{A N C}{A U} * E q N u m V\right)\right]+} \\
& b_{0}^{1}
\end{aligned}
$$


Figura 4 - Comparação entre consumos anuais de iluminação relacionando os três valores de DPI de Scalco et al. (2015) e as três categorias de desejabilidade de Heshong (2011)

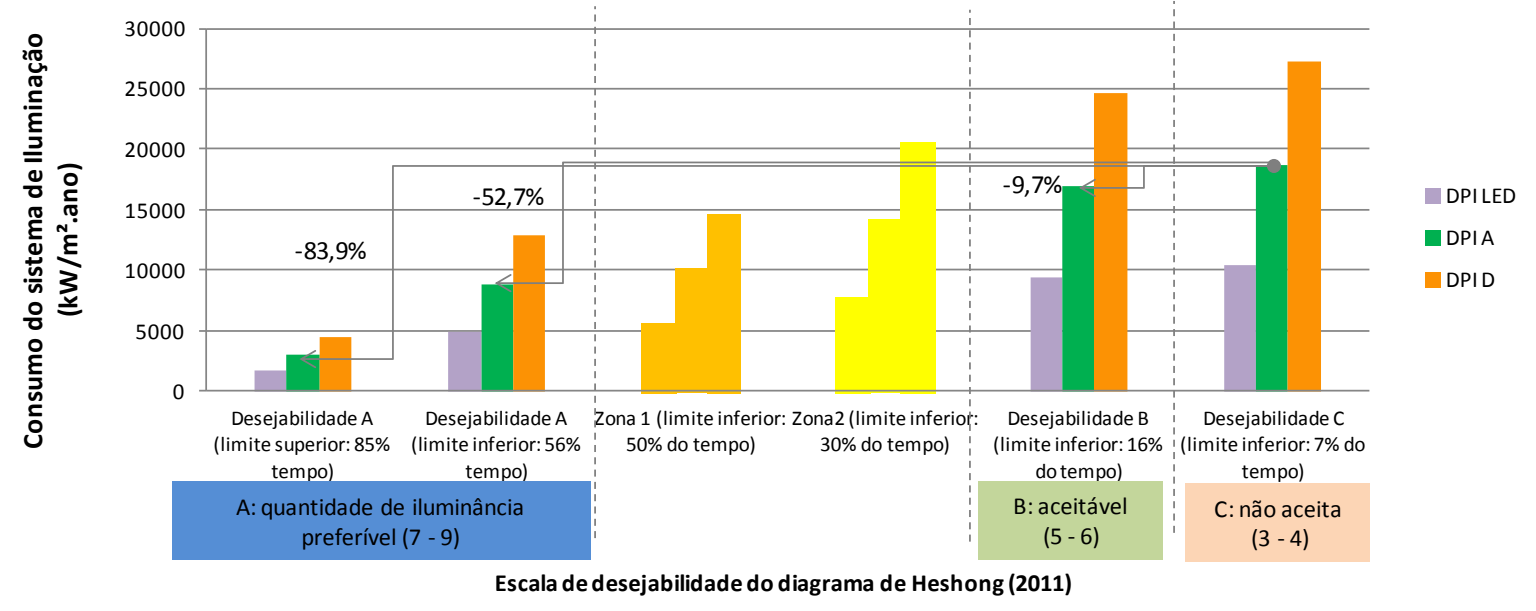

Durante o procedimento de determinação da eficiência do sistema de iluminação artificial, a DPI da edificação, que atualmente é comparada com as densidades de potência limite $\left(\mathrm{DPI}_{\mathrm{L}}\right)$, pode ser substituída pela DPU. Utilizando-se a abordagem apresentada, projetos que priorizem a iluminação natural podem ser mais bem valorizados. A utilização da DPU pode ser condicionada ao uso de controles de iluminação artificial. A locação desses controles deve ser vinculada ao zoneamento de iluminação natural (Zona 1 e Zona 2). Para diferentes tipos de controle, fatores de ajustes poderiam ser propostos. Ambientes que não disponham de sistemas de controle devem ser avaliados da forma vigente no regulamento. O cálculo da potência instalada do edifício completo deve ser feito da mesma forma; entretanto, em vez de considerar somente a potência instalada, os ambientes que aproveitam a iluminação natural podem utilizar a potência em uso. Com isso, a abreviação de equivalente numérico de iluminação, EqNumDPI, pode ser mais adequadamente adaptada para EqNumIL.

A rede neural adotada pode ser melhorada através do ajuste adequado do número de neurônios na camada interna e da ampliação do número de casos na amostragem. Dessa forma, pode-se melhorar sua confiabilidade para a previsão de casos nunca antes lhe apresentados. As equações da sequência metodológica são aplicáveis apenas a climas semelhantes ao de Florianópolis, devendo ser replicadas para ser utilizadas em outras localidades.

Por fim, a iluminação natural apresenta inúmeros outros benefícios, como o melhor índice de reprodução de cor (IRC), a relação com os aspectos biológicos e com a saúde humana, a relação com a produtividade e bem-estar do usuário, que não podem ser obtidos por meio de nenhuma fonte de iluminação artificial. Esses aspectos podem ser relacionados direta ou indiretamente com a eficiência energética, a exemplo dos IRCs, que, segundo Papamichael et al. (2015), quando elevados, podem compensar a necessidade de altos níveis de iluminância e, como resultado, reduzir o consumo de energia. Essa redução pode ser extremamente significativa, como foi apresentado na discussão sobre a adequabilidade dos níveis de iluminamento de acordo com as preferências do usuário.

\section{Conclusões}

O presente trabalho abordou uma aplicação de redes neurais artificiais como método simplificado para a previsão do impacto do aproveitamento da iluminação natural no consumo energético. O índice de iluminação natural adotado, IR $_{\mathrm{ILN}}$, possibilita o cálculo da densidade de potência instalada de iluminação em uso. Na proposta apresentada, o $\mathrm{IR}_{\mathrm{ILN}}$ foi combinado com um zoneamento de iluminação natural dinâmico para oferecer a DPU final de um ambiente. Foram discutidos o potencial energético da iluminação natural ante diferentes tecnologias de iluminação artificial e a relevância da definição de índices mínimos de iluminação natural, bem como seu impacto no consumo energético.

A integração da RNA com o zoneamento dinâmico de Fonseca (2015) permitiu uma rápida avaliação do ambiente, visto que os resultados de ambos são instantâneos. As principais contribuições do método simplificado aqui proposto são a consideração do dinamismo da luz e a flexibilidade quanto à forma dos ambientes e à iluminância de projeto. $\mathrm{O}$ erro obtido na validação da proposta apresentada, inferior a 5\%, foi considerado aceitável para um método simplificado em que a 
velocidade na aplicação e o caráter comparativo de soluções são priorizados ante a precisão.

A comparação dos resultados do estudo de caso com resultados de Scalco et al. (2015) permitiram confirmar o elevado potencial energético do aproveitamento da iluminação natural e seu impacto em certificações. A discussão sobre índices mínimos de iluminação natural relacionando conforto dos usuários com eficiência energética destacou a importância da definição desses índices na robustez do sistema de avaliação do desempenho de edifícios.

Por fim, a sequência metodológica apresentada é aplicável a qualquer localização, desde que devidamente replicada utilizando-se arquivo climático representativo. Como limitações da proposta, o zoneamento dinâmico não é aplicável à iluminação zenital e não considera proteções solares, entretanto esses elementos são contemplados na RNA, podendo ter seu escopo expandido em trabalhos futuros.

\section{Referências}

AMERICAN SOCIETY OF HEATING, REFRIGERATING AND AIR-CONDITIONING ENGINEERS. Standard 90.1: energy standard for buildings except low-rise residential buildings. Atlanta, 2013.

ASSAF, L. O.; PEREIRA, F. O. R. Perspectivas de la Eficiência Energética en la Iluminación:

Desafios Para el Desarrollo. In: ENCONTRO

NACIONAL SOBRE CONFORTO NO

AMBIENTE CONSTRUÍDO, 7 ;

CONFERÊNCIA LATINO-AMERICANA

SOBRE CONFORTO E DESEMPENHO

ENERGÉTICO NAS EDIFICAÇÕES, 3.,

Curitiba, 2003. Anais... Curitiba, 2003.

BOCANEGRA, C. W. R. Procedimento Para Tornar Mais Efetivo o Uso das Redes Neurais Artificiais em Planejamento de Transportes.

São Carlos, 2002. 97 f. Dissertação (Mestrado em Engenharia Civil) - Departamento de Engenharia Civil, Universidade de São Paulo, São Carlos, 2002.

CALIFORNIA ENERGY COMISSION. TITLE 24 - 2013 Building Energy Efficiency Standards for Residential and Nonresidential Buildings CEC-400-2012-004-CMF-REV2. California Energy Commission. Part 1. n. 252, 2013.

CARVALHO, A. P. L. F. Redes Neurais Artificiais: tutorial. Disponível em: $<$ http://conteudo.icmc.usp.br/pessoas/andre/researc h/neural/>. Acesso em: 11 mar. 2014.
COMMISSION INTERNATIONALE

D’ECLAIRAGE. CIE. TC 6-11. Draft "Ocular

Lighting Effects on Human Physiology, Mood and Behavior". Commission Internationale d'Eclairage, 2003.

ENERGY PERFORMANCE OF BUILDINGS DIRECTIVE. National Calculation Methodology (NMC) Modeling Guide (for Buildings Other than Dwellings in England). Department for Communities and Local Government, 2014.

FELIPPE, A. R. et al. Modelagem Paramétrica Para Simulação do Desempenho da Iluminação Natural e Termoenergético da Edificação. In: CONGRESSO DA SOCIEDADE IBEROAMERICANA DE GRÁFICA DIGITAL, 19. Florianópolis, 2015. Anais... São Paulo: Blucher, 2015.

FONSECA, R. W. Iluminação Natural e Consumo Energético de Edificações Não Residenciais: as possibilidades e as limitações da aplicação de redes neurais artificiais.

Florianópolis, 2015. 457 f. Tese (Doutorado em Engenharia Civil) - Departamento de Engenharia Civil, Universidade Federal de Santa Catarina, Florianópolis, 2015.

FONSECA, R. W.; DIDONÉ, E. L.; PEREIRA, F. O. R. Using Artificial Neural Networks to Predict the Impact of Daylighting on Building Final Electric Energy Requirements. Energy and Buildings, v. 61, p. 31-38, 2013.

HAYKIN, S. Redes Neurais: princípios e práticas. 2. ed. Porto Alegre: Artmed, 2001.

HESHONG, L. Daylight Metrics (CEC-5002012-053). Heshong Mahone Group - Public Interest Energy Research - California Energy Commission, 2011.

ILLUMINATING ENGINEERING SOCIETY OF NORTH AMERICA. Approved Method: IES Spatial Daylight Autonomy (sDA) and Annual Sunlight Exposure (ASE) - IES LM-83-12. New York: IESNA, 2012.

INSTITUTO NACIONAL DE METROLOGIA, QUALIDADE E TECNOLOGIA. Requisito Técnico da Qualidade Para o Nível de Eficiência Energética de Edifícios Comerciais, de Serviços e Públicos: portaria n. 372. Inmetro, 2010.

KALOGIROU, S. A. Artificial Neural Networks in Renewable Energy Systems Applications: a review. Renewable and Sustainable Energy Reviews, v. 5, n. 4, p. 373-401, 2001. 
KRARTI, M. An Overview of Artificial Intelligence-Based Methods for Building Energy Systems. Journal of Solar Energy Engineering, v. 125, n. 3, p. 331-342, 2003.

MAGOULÈS, F.; ZHAO, H.-X.; ELIZONDO, D. Development of an RDP Neural Network for Building Energy Consumption Fault Detection Diagnosis. Energy and Buildings, v. 62, p. 133138, 2013.

MATHWORKS INC. MatLab 2011: linguagem computacional técnica. Natick. 2011. Disponível em:

<http://www.mathworks.com/products/neuralnet/d escription1.html>. Acesso em: 25 jun. 2011.

MAYHOUB, M. S.; CARTER, D. J. Towards Hybrid Lighting Systems: a review. Lighting Research \& Technology, v. 42, n. 1, p. 51-71, 2010.

O'CONNOR, J. et al. Tips for Daylighting With Windows Report. Berkeley: Lawrence Berkeley National Laboratory, 1997.

PAPAMICHAEL, K. et al. High Color Rendering Can Enable Better Vision Without Requiring More Power. Leukos - Journal of Illuminating Engineering Society of North America, p. 1-12, mar. 2015.

PEREIRA, F. O. R. et al. An Investigation About the Consideration of Daylighting Along the Design Stages. In: PASSIVE AND LOW ENERGY ARCHITECTURE, Beirute, 2005. Proceedings... Beirute, 2005.
SCALCO, V. A. et al. Retrofit do Sistema de Iluminação em Edificações de Escritórios: potencial de economia de energia de acordo com método da Etiqueta PBE Edifica. Lumiere Eletrics, p. 13, maio 2015.

U.S. GREEN BUILDING COUNCIL. LEED v4 for Building Design and Construction. USGBC Inc., 2014.

UNITED STATES DEPARTMENT OF

ENERGY. EnergyPlus v.6. Programa de análise termoenergética detalhada. 2012.

WILLIAMS, A. et al. Lighting Controls in Commercial Buildings. Leukos - Journal of Illuminating Engineering Society of North America, v. 8, n. 3, p. 161-180, 2012.

WONG, S. L.; WAN, K. K. W.; LAM, T. N. T. Artificial Neural Networks for Energy Analysis of Office Buildings With Daylighting. Applied Energy, v. 87, n. 2, p. 551-557, 2010.

ZHAO, H.-X.; MAGOULÈS, F. A Review on the Prediction of Building Energy Consumption.

Renewable and Sustainable Energy Reviews, v. 16, n. 6, p. 3586-3592, 2012.

\section{Agradecimentos}

Os autores agradecem o apoio financeiro da Capes, do $\mathrm{CNPq}$ e da Eletrobras no âmbito do Convênio ECV-DTP 002/2011, celebrado entre a Eletrobras e a UFMG/UFSC.

Raphaela Walger da Fonseca

Laboratório de Conforto Ambiental | Universidade Federal de Santa Catarina | Trindade | Caixa Postal 476 | Florianópolis - SC - Brasil | CEP 88040-970 | Tel.: (48) 3721-4974 | E-mail: raphawf@gmail.com

Fernando Oscar Ruttkay Pereira

Departamento de Arquitetura, Centro Tecnológico | Universidade Federal de Santa Catarina | Tel.: (48) 9960-6541 |

E-mail: ruttkay.pereira@ufsc.br

Revista Ambiente Construído

Associação Nacional de Tecnologia do Ambiente Construído

Av. Osvaldo Aranha, $99-3^{\circ}$ andar, Centro

Porto Alegre - RS - Brasil

CEP $90035-190$

Telefone: +55 (51) 3308-4084

Fax: +55 (51) 3308-4054

www.seer.ufrgs.br/ambienteconstruido

E-mail: ambienteconstruido@ufrgs.br

68 Fonseca, R. W, da; Pereira, F. O. R. 